\title{
ENSINO DE MAPA DE RISCOS AMBIENTAIS COM O USO DO SOFTWARE LIBREOFFICE DRAW
}

\author{
TEACHING AN ENVIRONMENTAL RISK MAP USING THE LIBREOFFICE DRAW \\ SOFTWARE
}

\author{
Márcia Jussara Hepp Rehfeldt ${ }^{1}$, Cláudio Pereira da Silva ${ }^{2}$
}

Recebido: fevereiro/2019 Aprovado: setembro/2021

\begin{abstract}
Resumo: $O$ presente trabalho objetiva apresentar alguns resultados decorrentes do uso do software LibreOffice Draw, como estratégia pedagógica, para o ensino de mapa de riscos ambientais (setorial e geral). É parte integrante da dissertação de mestrado intitulada: 0 ensino de mapa de riscos ambientais com o uso de softwares. A prática foi desenvolvida com o uso desse software, com a participação de 20 alunos e 2 professores que atuam no curso técnico de Segurança do Trabalho, ofertado em uma instituição de ensino federal, localizada no interior do estado do Pará. Trata-se de uma pesquisa qualitativa, com procedimentos técnicos de pesquisaparticipante. No fazer pedagógico, a docência aconteceu de forma mediadora e os discentes foram orientados a buscar autonomia e colaboração nas aprendizagens. Os materiais de coleta de dados foram os mapas setoriais e gerais confeccionados pelos alunos, entrevistas, filmagens, fotografias, gravações das aulas e um questionário de opinião. Os resultados apontam que com esse software foi possível criar os mapas de riscos setoriais e gerais. O feedback, com base em critérios avaliativos formativos e as possibilidades ofertadas do fazer, do experimentar, do errar, do acertar, mas também do aprender auxiliou os alunos a melhorar as construções posteriores.
\end{abstract}

Palavras-chave: Desenho Técnico, Diagramação, Técnico em Segurança do Trabalho, Layout.

Abstract: This paper aims to present some results of representations made with the software LibreOffice Draw, as pedagogical strategy, for the teaching of environmental risk map (sectoral and general). It is part of a master dissertation entitled: The teaching of environmental risk map with the use of softwares. The practice was developed with the use of this software, with 20 students and 2 teachers who work in the technical course of Occupational Safety, offered in a federal education institution located in the interior of the state of Pará. It is a qualitative research, with technical procedures of participatory-research. In the pedagogical process, teaching took place in a mediating way and the students were guided to seek autonomy and collaboration in learning. The data collection materials were the sectoral and general maps made by the students, interviews, filming, photographs, class recordings and a questionnaire. The results show that it was possible to create sector and general risk maps. The feedback, based on formative evaluative criteria and the offered possibilities of doing, experimenting, making mistakes, hitting, but also learning helped students to improve later constructions.

Keywords: Technical Drawing, Diagramation, Occupational Safety, Layout.

\section{Introdução}

Nos dias atuais é difícil imaginar o desenvolvimento de qualquer ciência desprovida das ferramentas tecnológicas, principalmente na educação, que, em busca de melhores resultados

https://orcid.ora/0000-0002-0007-8639. Universidade federal do Rio Grande do SUl UFRGS. Professora da Universidade do Vale do Taquari - Univates, Lajeado, Rio Grande do Sul, Brasil. Rua Salgado Filho, 169, bairro Canabarro, Teutônia, RS, Brasil CEP 95890-000. E-mail: mrehfeld@univates.br

2 iD https://orcid.org/0000-0003-4373-8729. Fundação Universidade do Tocantins UNITINS. Docente do Instituto Federal de Educação, Ciência e Tecnologia do Pará - IFPA, Conceição do Araguaia, Pará, Brasil. Rua 30 de Maio no 1588, setor Universitário, Conceição do Araguaia, PA, Brasil, CEP 68.540-000. E-mail: claudio.silva@ifpa.edu.br. 
no ensino, necessita, cada vez mais, desses recursos para a modernização, melhoria e sistematização dos conhecimentos teóricos e práticos. Nesse contexto, Kenski (2007) disserta que as tecnologias servem para fazer educação, e que essas são indissociáveis, uma vez que estão presentes no dia a dia das pessoas e a educação não pode ser algo alheio ao que se passa no cotidiano das pessoas.

No entanto, não é só porque o mundo vivencia uma revolução tecnológica que os professores devem utilizar essas tecnologias de medíocre. A utilização de recursos tecnológicos como os softwares, por exemplo, requer planejamento focado nos resultados que se pretende alcançar. Nesse sentido, Tajra (2012) menciona que não é conveniente para o professor apenas explicar os recursos disponibilizados por um software e pedir para os alunos resolverem atividades com essas ferramentas. É recomendável utilizá-los para dinamizar as aulas de maneira criativa e inovadora, contextualizando-os com a realidade prática, de forma a despertar o interesse dos educandos, fomentando momentos que foquem no desenvolvimento intelectual e cognitivo desses alunos.

Contudo, as exigências mercantilistas sobre o domínio dessas ferramentas podem fazer com o que a informática seja inserida na matriz curricular dos cursos técnicos apenas para demonstrar que estes estão contemplando as tecnologias em seu currículo. Isso pode acarretar numa inserção dissociada dos demais componentes curriculares e da vivência pragmática desses alunos.

Em cursos técnicos de Segurança do Trabalho, por exemplo, essa realidade não é diferente. $O$ mercado de trabalho exige profissionais capacitados para trabalhar com diversas tecnologias, dentre essas, destacam-se as computacionais. Entende-se que elas são cada vez mais utilizadas no dia a dia desses profissionais, seja para fazer um simples check-list ou para elaborar um mapa de riscos ambientais.

Dessa forma, conhecer os resultados do uso de softwares como estratégia pedagógica para o ensino de mapa de riscos ambientais pode revelar informações importantes, que possibilitarão a tomada de novos rumos e ações didáticas anteriormente não percebidas. Assim, poder-se-á contribuir para a eficácia do ensino dessa temática no referido curso, além de promover a formação de profissionais e cidadãos atualizados e preparados para trabalhar com essas tecnologias.

Nesse contexto, esse estudo tem por objetivo relatar algumas implicações pedagógicas decorrentes do uso do software LibreOffice Draw, como estratégia de ensino de mapa de riscos ambientais (setorial e geral), no curso Técnico de Segurança do Trabalho, instituído em uma Instituição Federal, no sul do Pará.

\section{Algumas fundamentações teóricas}

Segundo Ponzeto (2010, p. 99), o mapa de riscos ambientais visa a "reunir informações necessárias para estabelecer o diagnóstico da situação de segurança e saúde do trabalho na empresa". Todas essas informações, organizadas e exibidas num mesmo elemento pictórico, são úteis no tocante à prevenção de possíveis acidentes de trabalho. 
No Brasil, o referido instrumento de prevenção de acidentes é regido pela NR-5 (Norma Regulamentadora 5). Quanto às instruções para elaboração do mapa de riscos, essas podem ser encontradas nos atuais manuais que tecem sobre segurança e medicina do trabalho que, segundo Ponzeto (2010, p. 18), são embasados na "Portaria no 25 de 29 de dezembro de 1994, que tem como objetivo instruir teoricamente como se elabora o Mapa".

Segundo Pepplow (2010, p. 132), "na elaboração do mapeamento de riscos foi convencionado utilizar círculos com três diferentes tamanhos, para determinar o grau de risco", esses são classificados em: grande, médio e pequeno. $O$ tamanho do círculo aumenta conforme a gravidade do risco e são preenchidos com as cores que representam cada risco identificado.

Para elaborar o mapa, é necessário elencar todos os possíveis riscos inerentes à saúde do trabalhador. Nesse sentido, Pepplow (2010, p. 131) explica que "o mapeamento de riscos referese à identificação dos riscos oferecidos pelo ambiente de trabalho". Essa identificação, segundo o autor, tem como objetivo principal fornecer ao trabalhador informações visuais suficientes e acessíveis sobre os riscos existentes em cada setor do trabalho. Pepplow (2010) ainda explica que nesse arranjo gráfico, os riscos físicos são representados pela cor verde, os químicos pela cor vermelha, os biológicos pela cor marrom, os ergonômicos pela cor amarela e os riscos de acidentes pela cor azul.

Segundo Ponzeto (2010), os mapas de riscos podem ser classificados em dois modelos: Setorial ou Geral. Para Ponzeto (2010, p. 110), um mapa de risco setorial traz os seguintes esclarecimentos: "Abrange todos os setores da empresa de forma mais específica para cada risco, possuindo, portanto, muitas informações relacionadas aos riscos setoriais, recomendações e procedimentos a serem seguidos". Já o mapa de riscos geral abrange uma área maior ou vários ambientes. Segundo Ponzeto (2010, p. 112), "Esse modelo permite uma visão geral dos ambientes de trabalho, auxiliando os trabalhadores a identificar facilmente os riscos aos quais estão expostos".

Com relação ao ensino do mapa de riscos ambientais no curso técnico em Segurança do Trabalho, dentre os vários conteúdos abordados, esse é um que envolve tanto conhecimentos teóricos quanto práticos. Dessa forma, o professor ao abordar essa temática, precisa considerar alguns pontos fundamentais antes de utilizar uma estratégia de ensino. Dentre esses, Rangel (2005) recomenda cuidados e critérios fundamentados tanto na escolha, como no planejamento da técnica a ser utilizada. Na escolha, é recomendável levar em consideração fatores didáticos que respondam como, quando, o que e para quem será ensinado.

Seja qual for a estratégia utilizada, Giraffa (2013 p. 108) disserta que "precisamos criar estratégias para estimular os alunos a fazer associações entre o seu comportamento fora da escola e o esperado na sua educação formal". Assim, os educandos possivelmente atribuirão maior notoriedade à estratégia, quando o professor estrategista agregar importâncias educacionais condizentes com a vida e valores desses alunos.

Dentre as diversas estratégias que podem ser exploradas pelos docentes, o uso de softwares pode ser uma opção, pois Nascimento (2007, p. 39) argumenta que "as utilidades e os benefícios no desenvolvimento de diversas habilidades fazem do computador, hoje, um 
importante recurso pedagógico", principalmente porque disponibiliza softwares que podem ser utilizados em diversas áreas do conhecimento.

Contudo, é primordial que, antes do docente começar a usar um aplicativo em sala de aula, ele realize testes, entenda seus recursos e, a partir destas observações, elabore um planejamento que vise à mediação e à construção do conhecimento aos discentes (MASSETO, 2012).

Nessa conjuntura didática-tecnológica, a estratégia de ensino de mapa de riscos, por meio de software, pode ser uma solução viável, pois segundo Ponzeto (2010), a elaboração do mapa pode ser feita por meio de vários softwares e cita como exemplos: PowerPoint, Word, CorelDraw e AutoCad. No entanto, esses aplicativos não oferecem gratuidade e alguns como PowerPoint e Word oferecem poucos recursos gráficos para elaboração dos layouts dos mapas. Distintamente, o software LibreOffice Draw, além de ser gratuito, pode fornecer recursos didáticos relevantes para ensino desse conteúdo.

Segundo Afonso (2013a, p. 4), o LibreOffice Draw “é uma ferramenta de desenho vetorial que permite realizar tudo desde um simples diagrama ou fluxogramas até desenhos artísticos em três dimensões". Por ser uma ferramenta baseada em vetores, as figuras geradas a partir dela não perdem qualidade quando ampliadas, pois as fórmulas matemáticas desenvolvidas para esse software calculam a ampliação proporcionalmente à escala do novo redimensionamento. Além disso, os arquivos criados são leves e ocupam menos espaços na memória do computador do que outros gráficos não vetoriais.

Dentre esses pontos citados pelo autor, destaca-se a gratuidade desse sistema, pois é um software livre. De acordo com Afonso (2013b, p. 6), "software livre é, segundo a definição criada pela Free Software Foundation, qualquer programa de computador que pode ser usado, copiado, estudado e redistribuído com algumas restrições". Essas especificidades de usabilidade, estudo e distribuição livre propiciam o uso dessa ferramenta no meio acadêmico, pois abre espaço significativo para novas pesquisas, além de permitir que os discentes a utilizem fora do ambiente acadêmico, ou até instalem em seus computadores pessoais, o que possivelmente os motivará a continuar usando essas ferramentas, mesmo após a conclusão do curso.

O LibreOffice Draw e os demais softwares que compõem o pacote LibreOffice estão disponíveis para download em http://pt.libreoffice.org/transferir-e-instalar/transferencias/, tendo sido desenvolvidas versões para os sistemas operacionais: Windows, Linux e MacOS (AFONSO, 2013a). A versão do software utilizado na presente pesquisa é a versão 4.2.1.1, que já conta com a ferramenta Smart Connector, a qual permite definir num desenho, os pontos de ligação entre os vértices, podendo ser inseridos ou excluídos a qualquer momento. Esse recurso permite criar diversos desenhos como diagramas, organogramas, além de muitas outras possibilidades de criações pictóricas como, por exemplo, o mapa de riscos. 


\section{Caminhos metodológicos}

Trata-se de uma pesquisa qualitativa, com procedimentos técnicos de pesquisa participante. De acordo com Haguete, 1990, p. 63), uma pesquisa participante é aquela em que o pesquisador está constantemente no ambiente investigado e pode "ver as coisas por dentro". Ainda, o "[...] investigador compartilha de modo consistente e sistematizado das atividades do grupo ou do contexto que está sendo estudado, ou seja, ele se envolve nas atividades, além de compartilhar 'interesses e fatos'" (HAGUETE, 1990, p. 63).

A intervenção foi desenvolvida durante dois meses, com uma turma do curso Técnico de Segurança do Trabalho, ofertado por uma instituição de ensino federal, localizada no interior do estado do Pará. Participaram desta pesquisa 20 alunos e dois professores que ministram as disciplinas de Prevenção e Controle de Risco (que auxiliou nas orientações acerca de mapas de risco) e Informática Aplicada, sendo esta última ministrada pelo segundo autor do artigo. As atividades desenvolvidas com os alunos foram: a) apresentação de modelos de mapas de risco setorial e geral e alguns softwares recomendados para a elaboração dos referidos mapas; b) visitação a instalações prediais dos laboratórios e aferições de medidas dos equipamentos e ambientes que seriam representados nos mapas; c) conversas com os responsáveis dos setores para obterem maiores informações sobre os possíveis riscos e com o professor da disciplina Prevenção e Controle de Risco; d) exploração das principais ferramentas do software LibreOffice Draw que seriam necessárias para a confecção de um mapa de riscos, tais como círculos e formas ovais, barra de ferramenta desenho, linha e preenchimento, medições com a régua e outras; e) representação de mapas de risco setoriais e geral, a partir dos dados coletados na ocasião das visitas aos laboratórios; f) criação de quadro de desempenho e principais itens que deveriam constar para fins de feedback aos alunos; e g) avaliação do software LibreOffice Draw.

Especificamente, no fazer pedagógico, os alunos foram desafiados a elaborar, com o uso do software LibreOffice Draw, inicialmente um mapa de riscos setorial dos laboratórios da própria instituição onde eles estudam e, posteriormente, um mapa de risco geral, englobando todos os laboratórios. $\mathrm{O}$ intuito foi propor atividades que tivessem significados práticos, de acordo com a vivência desses alunos.

Para a coleta de dados foram utilizados os materiais produzidos pelos alunos (mapas setoriais e gerais), entrevistas, questionários, observação participante, fotografias e filmagens. Contudo, visando garantir o anonimato e a integridade dos sujeitos envolvidos na pesquisa, no decorrer das discussões tecidas nas análises, os sujeitos não foram identificados pelos nomes, mas como Aluno 1, Aluno 2 e, assim, por diante.

\section{Análise e discussão dos dados}

Ao realizarem a visita aos laboratórios, os alunos foram orientados para que descrevessem, no layout, o máximo possível de informações acerca das máquinas, equipamentos ou instrumentos contidos no setor, uma vez que, segundo Ponzeto (2010, p. 114), "[...] essas informações deverão estar contidas no layout do setor", e, consequentemente, no mapa de risco setorial. Para tal, os alunos fotografaram cada equipamento, mobília e outras possíveis fontes de riscos. Com essas fotos e rascunhos de layouts, os alunos procuravam os 
técnicos responsáveis por cada laboratório e entrevistaram tais profissionais. A finalidade dessas entrevistas foi obter maiores informações sobre os possíveis riscos desses aparelhos ou mesmo outras ameaças inerentes ao setor.

Com as medidas em mãos e com as informações iniciais de como opera o software LibreOffice Draw, os alunos iniciaram os desenhos de seus mapas setoriais. Os Alunos 2, 8, 11, 15, 17 e 20 terminaram os mapas bem antes dos demais, aproximadamente uma hora de diferença. Esses discentes demonstravam ter mais conhecimentos prévios em informática que os demais colegas. Então, a estratégia adotada foi solicitar que esses discentes utilizassem o tempo restante para explorar outros modelos de mapa de riscos e, se possível, também ajudassem os colegas da turma que ainda não haviam concluído. Um dos mapas setoriais produzidos para o laboratório de entomologia foi elaborado pelo Aluno 8 e está representado na Figura 1. Já o Aluno 12 produziu um mapa de risco setorial do setor laboratório de solos (Figura 2).

\section{PROTEÇÃO COLETIVA} Sinalizaçäo de saida de emergència, aterramento dos equipamentos elétrico electớnicos e Diálogo diario de segurança.

PROTEÇÃO INDIVIDUAL

Oculos protetores, máscara, luvas de borracha, jaleco de mangas compridas, calçados fechados de borracha e luvas de raspa de couro, substituiça das banquetas de madeira por cadeira com apoio de braços e regulagem de altura $\theta$ posiçą̆o de encosto.
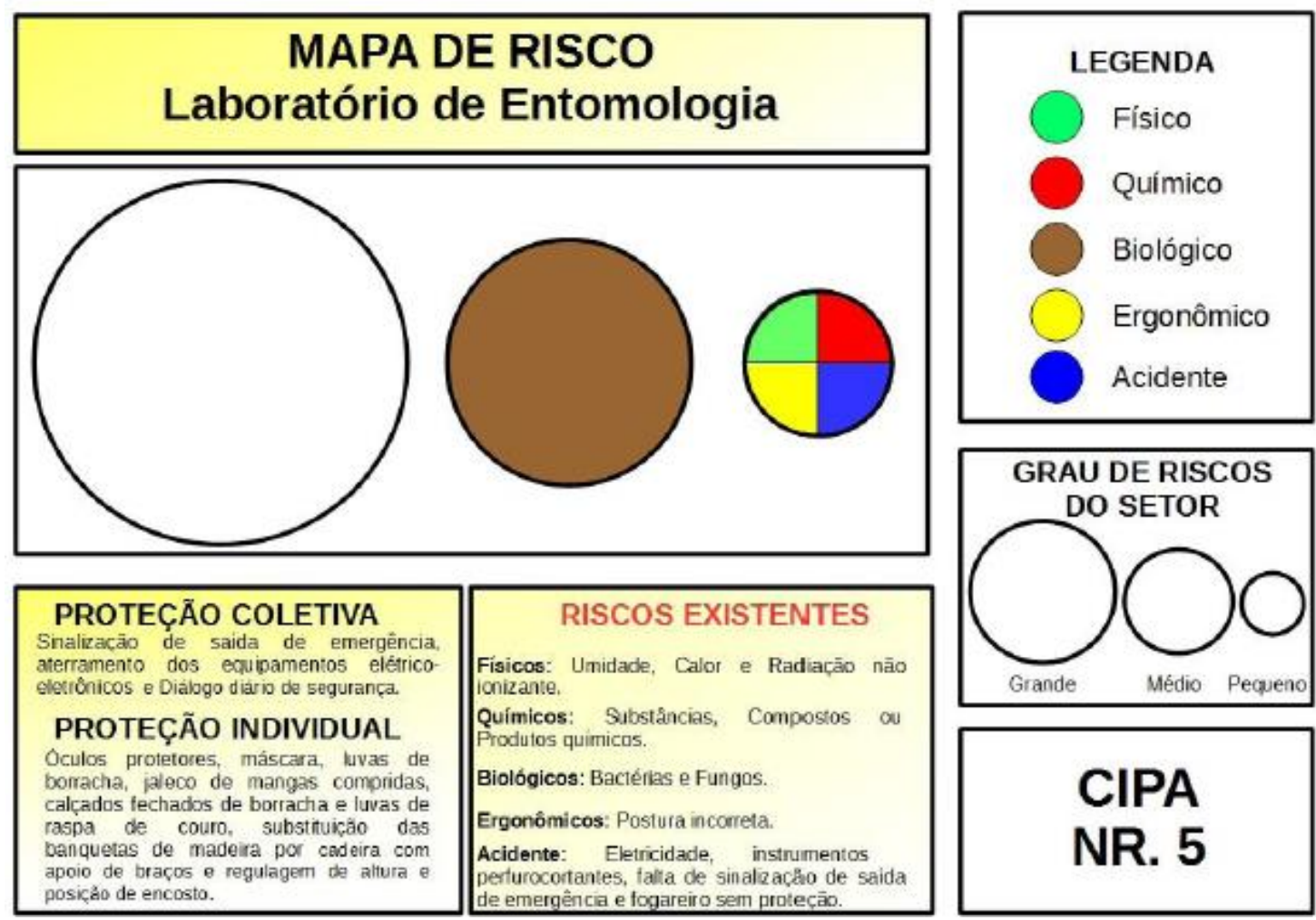

Figura 1 - Mapa setorial do laboratório de entomologia produzido pelo Aluno 8

Fonte: LibreOffice Draw (2015), autoria do Aluno 8 


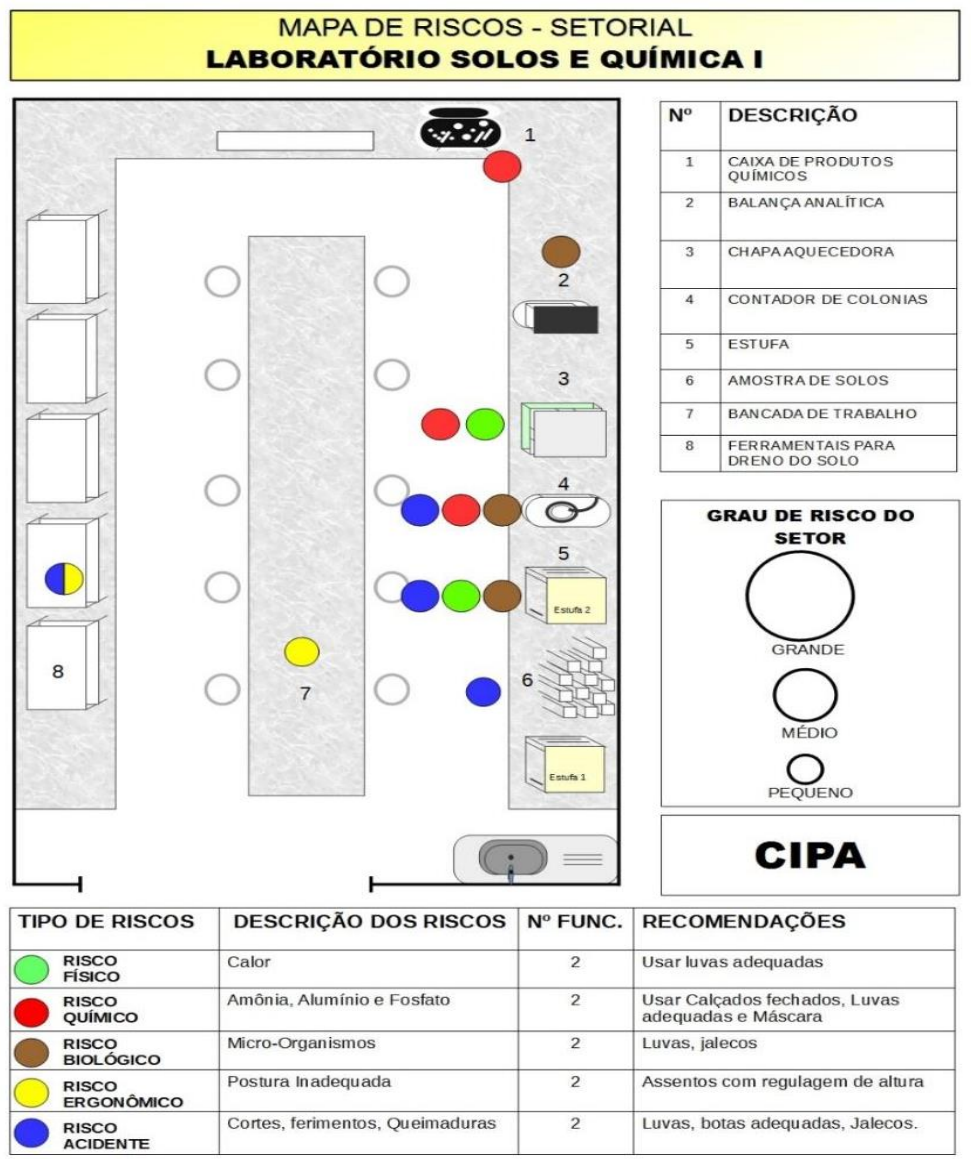

Figura 2 - Mapa de riscos setorial do laboratório de solos e química I criado a partir do Layout

Fonte: LibreOffice Draw (2015), autoria do Aluno 12

A partir das duas figuras pode-se observar que houve diferenças nas disposições dos elementos nos mapas. Cabe ressaltar que não foi fornecido, previamente à atividade, nenhum modelo de mapa e que os discentes foram responsáveis por pesquisá-los. No entanto, ao longo da prática, algumas observações foram realizadas, objetivando melhoria das representações. Em decorrência dessa flexibilidade nas estratégias, todos os discentes conseguiram finalizar a confecção dos mapas, alguns com maior riqueza de detalhes e outros, menor. Inclusive, os discentes expressavam frases como, por exemplo: "Professor, foi trabalhoso, mas foi muito bom oh" (Aluna 16) e "De tanto, fazer, desfazer, fazer de novo, já aprendi até as cores desses riscos" (Aluna 4).

Contudo, ao analisar todos os mapas criados, percebeu-se que havia a necessidade de fornecer aos discentes um retorno avaliativo sobre essas produções, ou seja, uma avaliação de caráter formativo, que apresentasse um feedback sobre o desempenho desses alunos na elaboração desses instrumentais. Nesse sentido Garcia (2009, p. 211) disserta:

As escolhas exercidas pelos professores podem ampliar ou limitar as oportunidades para que os estudantes demonstrem o que aprenderam. Além disso, as práticas de avaliação podem ser mais ou menos restritivas em relação à possibilidade de fornecer feedback ao aluno sobre seu desempenho durante o processo de ensino-aprendizagem. Tais aspectos são 
fundamentais na atualidade, considerando a importância que as práticas de avaliação formativa vêm conquistando.

Dessa forma, optou-se por avaliar a produtividade dos alunos considerando indicadores específicos e se tais indicadores foram contemplados total ou parcialmente, ou ainda, se estavam ausentes nos mapas. Assim, o Quadro 1 retrata a avaliação holística realizada no qual "Sim" significa que o item foi contemplado; "parc" significa parcialmente; e "não", representa elemento ausente. Cabe salientar que os indicadores usados são os principais elementos de um mapa de risco, pois são exigidos pelas normatizações vigentes, bem como impactam diretamente na interface visual do mapa. Sendo assim, acredita-se ser importante que eles sejam avaliados e utilizados como indicadores de produtividade.

\begin{tabular}{|c|c|c|c|c|c|c|c|c|c|c|c|}
\hline & 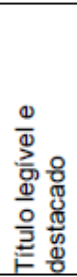 & 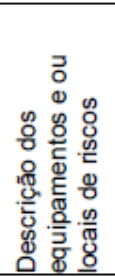 & 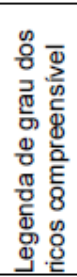 & 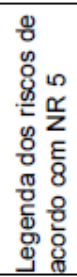 & 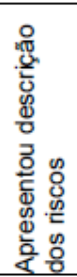 & 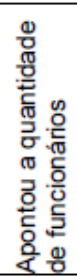 & 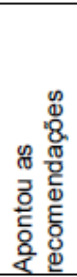 & 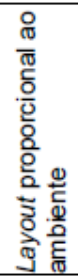 & 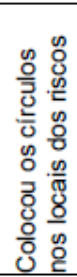 & 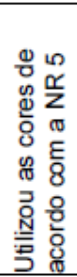 & 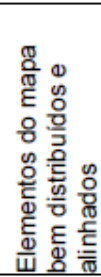 \\
\hline Aluno 1 & sim & sim & $\operatorname{sim}$ & sim & parc & sim & parc & sim & parc & sim & parc \\
\hline Aluno 2 & sim & sim & $\operatorname{sim}$ & sim & sim & sim & sim & sim & sim & sim & sim \\
\hline Aluno 3 & $\operatorname{sim}$ & sim & Parc & parc & parc & sim & não & sim & sim & sim & parc \\
\hline Aluno 4 & sim & $\operatorname{sim}$ & sim & sim & sim & $\operatorname{sim}$ & sim & $\operatorname{sim}$ & sim & $\operatorname{sim}$ & parc \\
\hline Aluno 5 & parc & $\operatorname{sim}$ & parc & sim & parc & sim & não & sim & parc & sim & parc \\
\hline Aluno 6 & sim & sim & sim & $\operatorname{sim}$ & sim & $\operatorname{sim}$ & parc & parc & sim & sim & parc \\
\hline Aluno 7 & parc & parc & sim & sim & parc & sim & sim & sim & sim & sim & sim \\
\hline Aluno 8 & sim & sim & sim & sim & sim & $\operatorname{sim}$ & $\operatorname{sim}$ & $\operatorname{sim}$ & sim & $\operatorname{sim}$ & sim \\
\hline Aluno 9 & sim & sim & parc & sim & sim & sim & sim & sim & sim & sim & parc \\
\hline Aluno 10 & $\operatorname{sim}$ & parc & sim & $\operatorname{sim}$ & parc & $\operatorname{sim}$ & $\operatorname{sim}$ & $\operatorname{sim}$ & sim & $\operatorname{sim}$ & parc \\
\hline Aluno 11 & sim & sim & $\operatorname{sim}$ & $\operatorname{sim}$ & sim & $\operatorname{sim}$ & $\operatorname{sim}$ & $\operatorname{sim}$ & sim & $\operatorname{sim}$ & sim \\
\hline Aluno 12 & sim & sim & sim & sim & sim & sim & sim & sim & sim & sim & sim \\
\hline Aluno 13 & sim & $\operatorname{sim}$ & $\operatorname{sim}$ & $\operatorname{sim}$ & $\operatorname{sim}$ & $\operatorname{sim}$ & parc & $\operatorname{sim}$ & sim & $\operatorname{sim}$ & parc \\
\hline Aluno 14 & sim & sim & sim & sim & sim & sim & sim & sim & sim & $\operatorname{sim}$ & sim \\
\hline Aluno 15 & sim & $\operatorname{sim}$ & $\operatorname{sim}$ & $\operatorname{sim}$ & sim & sim & $\operatorname{sim}$ & $\operatorname{sim}$ & $\operatorname{sim}$ & $\operatorname{sim}$ & sim \\
\hline Aluno 16 & sim & parc & sim & sim & parc & sim & $\operatorname{sim}$ & $\operatorname{sim}$ & sim & $\operatorname{sim}$ & parc \\
\hline Aluno 17 & sim & sim & $\operatorname{sim}$ & sim & sim & sim & sim & $\operatorname{sim}$ & $\operatorname{sim}$ & $\operatorname{sim}$ & sim \\
\hline Aluno 18 & parc & sim & sim & sim & parc & sim & parc & parc & parc & sim & parc \\
\hline Aluno 19 & sim & $\operatorname{sim}$ & sim & sim & parc & sim & parc & sim & sim & $\operatorname{sim}$ & parc \\
\hline Aluno 20 & sim & $\operatorname{sim}$ & sim & sim & sim & $\operatorname{sim}$ & sim & sim & sim & sim & $\operatorname{sim}$ \\
\hline
\end{tabular}

Quadro 1 - Avaliação holística realizada dos mapas setoriais entregues ao professor

Fonte: Autores do texto, 2018.

Por meio deste quadro foi possível verificar as partes do mapa que os alunos realizaram com sucesso e àquelas em que apresentaram alguma dificuldade. Dentre esses requisitos avaliados, o item "Elementos do mapa bem distribuídos e alinhados" apresentou dados que merecem uma análise mais detalhada, uma vez que somente 9 alunos cumpriram satisfatoriamente esse requisito. Ou seja, dentre 20 alunos, nove tiveram o cuidado ou a destreza de desenhar o mapa observando os pequenos detalhes, que são fundamentais para a visualização final, e correta interpretação do mapa. Por outro lado, 11 alunos, ou seja, a maioria da turma apresentou alguma dificuldade em atender esse requisito. Dentre as inadequações foram observados círculos não alinhados, falta de acentuação em palavras, entre outros. Dessa forma, fez-se necessário trabalhar especificamente esse aspecto com mais afinco nessa turma. Cabe frisar que durante a prática, os alunos eram orientados a melhorar seus mapas de acordo com a lista de itens destacados no Quadro 1. Ademais, ao final da prática, os alunos partilharam 
seus mapas com os colegas, para que todos pudessem observar os riscos existentes nos laboratórios da instituição em que estudavam.

Após encerrada a prática pedagógica de construção de mapas de risco setoriais, outra atividade foi desenvolvida: a representação do mapa de riscos geral, uma vez que os setores já haviam sido representados pelos mapas dos setores. De acordo com as orientações de Ponzeto (2010), o ideal é apresentar o mapa de riscos geral nos formatos A-0 ou A-1. Nessa classificação, o A-0 corresponde ao tamanho de $84,10 \mathrm{~cm}$ de largura por $118,90 \mathrm{~cm}$ de altura, já o formato A1 corresponde a 59,40 cm de largura por $84,10 \mathrm{~cm}$ de altura. Neste contexto, a turma preferiu elaborar o mapa seguindo o formato A-0. Inicialmente, a página foi formatada para o tamanho escolhido. A seguir, o mapa foi desenhado na escala 1:100, ou seja, cada metro representa $1 \mathrm{~cm}$ no desenho do mapa. Caso houvesse necessidade de ampliação posterior, isso poderia ser realizado sem prejuízo para a resolução da parte gráfica, pois, de acordo com Afonso (2013a), os desenhos produzidos neste software são vetoriais, o que garante boa qualidade nas imagens mesmo quando são ampliadas.

No que tange à prática, no decorrer das atividades, os discentes foram orientados para que, ao confeccionar os mapas gerais, procurassem fazer maior uso das guias do software LibreOffice Draw, no sentido de ajustar o alinhamento dos objetos, uma vez que, anteriormente, eles estavam utilizando as guias somente para fazer as medições dos espaços. Destaca-se que o fato da guia não ter sido utilizada no mapa setorial pode ter sido um dos motivos da falta de alinhamento. Na Figura 3 está representado um mapa de riscos geral. É possível observar que o Aluno 15 desenhou, com detalhes, todos os laboratórios, identificando os riscos existentes.

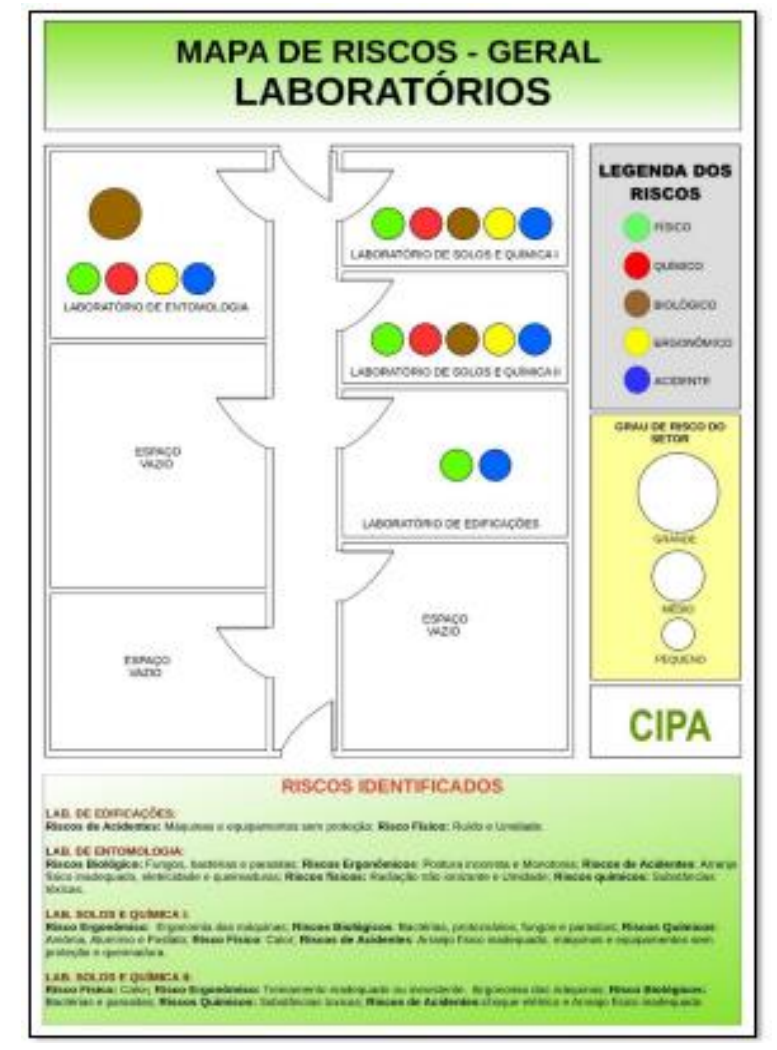

Figura 3 - Representação do mapa de riscos geral desenvolvido pelo Aluno 15 Fonte: LibreOffice Draw (2015), autoria do Aluno 15. 
De forma similar aos mapas setoriais, foi organizado o Quadro 2, o qual descreve os critérios de avaliação dos mapas gerais, bem como se tais critérios foram atendidos.

\begin{tabular}{|c|c|c|c|c|c|c|c|c|c|c|}
\hline & 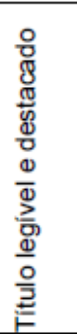 & 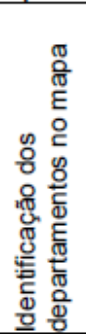 & 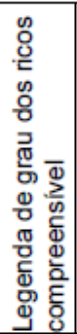 & 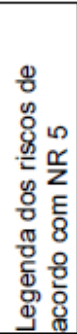 & 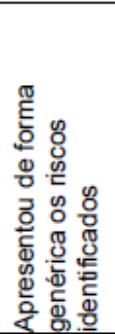 & 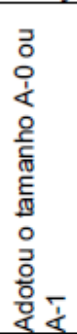 & 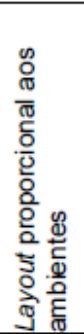 & 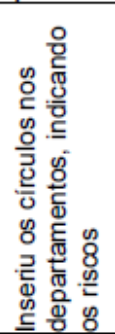 & 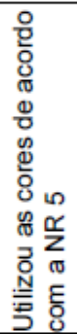 & 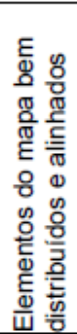 \\
\hline Aluno 1 & parc & sim & sim & sim & sim & $\operatorname{sim}$ & sim & sim & sim & sim \\
\hline Aluno 2 & sim & sim & sim & sim & sim & sim & sim & sim & sim & sim \\
\hline Aluno 3 & sim & sim & parc & sim & $\operatorname{sim}$ & sim & sim & $\operatorname{sim}$ & $\operatorname{sim}$ & $\operatorname{sim}$ \\
\hline Aluno 4 & sim & sim & sim & sim & sim & sim & sim & sim & sim & sim \\
\hline Aluno 5 & parc & sim & parc & sim & sim & sim & parc & sim & sim & parc \\
\hline Aluno 6 & sim & sim & sim & sim & sim & sim & sim & sim & sim & sim \\
\hline Aluno 7 & $\operatorname{sim}$ & sim & sim & sim & sim & sim & sim & sim & sim & sim \\
\hline Aluno 8 & sim & sim & sim & sim & $\operatorname{sim}$ & $\operatorname{sim}$ & $\operatorname{sim}$ & sim & sim & $\operatorname{sim}$ \\
\hline Aluno 9 & sim & sim & sim & sim & sim & sim & sim & sim & sim & sim \\
\hline Aluno 10 & sim & sim & sim & sim & parc & $\operatorname{sim}$ & sim & sim & sim & sim \\
\hline Aluno 11 & sim & sim & sim & sim & sim & sim & sim & sim & sim & sim \\
\hline Aluno 12 & sim & sim & sim & sim & sim & sim & sim & sim & sim & sim \\
\hline Aluno 13 & sim & sim & $\operatorname{sim}$ & $\operatorname{sim}$ & $\operatorname{sim}$ & $\operatorname{sim}$ & $\operatorname{sim}$ & $\operatorname{sim}$ & $\operatorname{sim}$ & sim \\
\hline Aluno 14 & sim & sim & sim & sim & sim & sim & sim & sim & sim & sim \\
\hline Aluno 15 & sim & sim & sim & sim & $\operatorname{sim}$ & $\operatorname{sim}$ & $\operatorname{sim}$ & $\operatorname{sim}$ & $\operatorname{sim}$ & $\operatorname{sim}$ \\
\hline Aluno 16 & sim & Sim & sim & $\operatorname{sim}$ & $\operatorname{sim}$ & $\operatorname{sim}$ & $\operatorname{sim}$ & $\operatorname{sim}$ & $\operatorname{sim}$ & $\operatorname{sim}$ \\
\hline Aluno 17 & sim & sim & sim & sim & sim & sim & sim & sim & sim & sim \\
\hline Aluno 18 & parc & sim & parc & sim & parc & sim & parc & sim & sim & parc \\
\hline Aluno 19 & sim & sim & sim & sim & sim & sim & sim & sim & sim & sim \\
\hline Aluno 20 & $\operatorname{sim}$ & sim & sim & $\operatorname{sim}$ & $\operatorname{sim}$ & $\operatorname{sim}$ & $\operatorname{sim}$ & $\operatorname{sim}$ & $\operatorname{sim}$ & $\operatorname{sim}$ \\
\hline
\end{tabular}

Quadro 2 - Avaliação holística realizada dos mapas gerais entregues ao professor

Fonte: Autores do texto, 2018.

Ao analisar o Quadro 2 e comparando-o com o Quadro 1, percebe-se que os discentes adquiriram ou aperfeiçoaram algumas habilidades importantes para o desenvolvimento de um mapa de risco. Um exemplo do progresso dos alunos ficou evidenciado ao observar que, na confeç̧ão do segundo mapa, mais alunos atentaram-se ao indicador que aponta se os elementos do mapa foram bem distribuídos e alinhados. Isso pode ter relação com os constantes feedbacks dados, bem como o desenvolvimento de novas habilidades a partir do software LibreOffice Draw. A exceção foram os alunos 5 e 18 que ainda apresentaram dificuldades operacionais na realização das atividades, mas, os demais discentes conseguiram cumprir com êxito esse requisito. Ao final, de forma semelhante a atividade anterior, os discentes foram convidados a partilhar suas aprendizagens com os colegas, socializando as representações realizadas.

Quanto ao software LibreOffice Draw, ressalta-se que o próprio website do LibreOffice destaca que a aplicação Draw "[...] fornece os meios para se comunicar com gráficos e diagramas. [...], mesmo se você não é um artista naturalmente talentoso." (LIBREOFFICE, s.d., texto digital). De fato, o presente estudo demonstrou que o software LibreOffice Draw é uma ferramenta que permitiu concretizar as ações de desenhar, representar e, por meio dele, o aluno colocou em prática o que aprendeu na teoria e produziu um produto final, no caso, um mapa de riscos, mostrando alguns indícios de que pode ter existido aprendizagem. 
Ademais, conforme mencionado na metodologia do estudo, posteriormente à confecção dos mapas, os alunos responderam a um questionário acerca da experiência de trabalhar com o software. Em um item do questionário, os discentes responderam à seguinte indagação: "O uso do software LibreOffice Draw contribuiu de alguma forma para sua aprendizagem sobre mapa de riscos? Caso afirmativo, como foi essa contribuição?". No retorno dos alunos observou-se uma unanimidade de respostas positivas, confirmando que, de uma forma ou de outra, esse software contribuiu para a aprendizagem da temática em estudo. Quando questionados sobre como ocorreu essa contribuição, algumas respostas apresentadas foram:

Aluno 2: "Sim. Na formação dos layout's [sic] dos setores, na representação dos riscos nesses setores."

Aluno 5: "Sim. Pela possibilidade de se ter a visão real do mapa, além disso, permite exercitar a construção do mapa."

Aluno 6: "Sim. Na confeç̧ão do mapa e nas informações dos equipamentos que geravam algum tipo de risco."

Essas respostas, conforme exemplificado pelos retornos dos alunos 2, 5 e 6, ilustram que as atividades contribuíram de alguma forma com ações que geraram possíveis aprendizagens. Nesse âmbito, destacam-se alguns verbos referentes às ações suscitadas nas falas desses alunos: Construir, formar, desenhar, representar, visualizar e confeccionar. São verbos que expressam ações cognitivas oriundas da prática, do fazer, do experimentar, do errar, do acertar, mas também do aprender. Portanto, diante dos resultados apresentados e das discussões tecidas, observa-se que o software LibreOffice Draw oportunizou ampliação de conhecimento na construção de mapas de riscos ambientais.

\section{Considerações finais}

Apesar das ações desenvolvidas terem sido consideradas um pouco complexas pelos discentes, constatou-se engajamento e participação ativa dos alunos na realização das atividades. De certo modo, o ato de fazer, desfazer e fazer novamente, proporcionado pelas ferramentas do software, oportunizou aos discentes um ambiente propício à construção do conhecimento. Outro aspecto importante foi o feedback proporcionado aos discentes. Por meio dele, foi possível observar uma melhora na representação do mapa de riscos geral. Portanto, pode-se inferir que ele é uma boa ferramenta para auxiliar na prática e no aprofundamento dos conhecimentos inerentes aos mapas de riscos.

Em adição, cabe comentar que durante as atividades com o uso desse software, observouse que os alunos pouco se atrasavam, os faltosos evitavam se ausentar, os desmotivados se mostraram com novos entusiasmos. Além disso, a teoria estudada foi colocada em prática e, assim, um conjunto de conhecimentos que antes parecia desarticulado da realidade foi concretizado numa vivência profissional desses futuros técnicos. Ainda, foi possibilitada a construção de mapas de distintos setores, conforme aferições realizadas pelos discentes, o que proporcionou uma visão geral dos laboratórios e auxiliou na confecção dos mapas gerais. Dessa 
forma, entende-se que a utilização desse software, aliada a uma metodologia de ensino condizente com a realidade prática desses discentes, foi, no mínimo, prazerosa.

Destarte, diante de tantas abordagens bibliográficas que defendem a utilização das tecnologias computacionais na educação; diante de tantos resultados pedagógicos positivos apontados pelos discentes da referida pesquisa, pode-se inferir que uso desse software pode ser uma estratégia viável ao ensino de mapa de riscos setoriais e gerais. Em suma, as referidas ferramentas computacionais, quando usadas de forma planejada, proporcionam novas formas de aprender e também de ensinar. Além disso, oportunizam ações pedagógicas que surpreendem, estimulam e desafiam os estudantes a todo o momento a colocarem na prática o que já estudaram na teoria.

Por fim, evidenciando o objetivo desta pesquisa qual seja, relatar algumas implicações pedagógicas decorrentes do uso do software LibreOffice Draw, como estratégia de ensino de mapa de riscos ambientais (setorial e geral), no curso Técnico de Segurança do Trabalho, podese inferir que ele auxiliou na construção de mapas de riscos, evidenciando ser uma alternativa de recursos quando os alunos efetivamente irão exercer sua profissão. Ainda, nas aulas em que tal recurso foi utilizado, percebeu-se a motivação dos alunos, uma vez que eles evitavam faltar e realizavam as atividades com entusiasmo.

\section{Referências}

AFONSO, Adriano et al. Guia de Iniciação ao LibreOffice: Coleção Manual TIC e LibreOffice. ISCTE-Instituto Universitário de Lisboa, 2013a. Disponível em: http://universolinux.org/wpcontent/uploads/2014/03/libreoffice-manual-pt.pdf. Acesso em: 11 nov. 2014.

. Manual Aberto de TIC e LibreOffice. ISCTE-Instituto Universitário de Lisboa, 2013b. Disponível em: http://universolinux.org/wp-content/uploads/2014/03/libreoffice-manualpt.pdf. Acesso em: 11 nov. 2014.

GIRAFFA, Lucia MM. Jornada nas Escol@s: A nova geração de professores e alunos.

Tecnologias, Sociedade e Conhecimento, v. 1, n. 1, p. 100-118, 2013.

HAGUETTE, Teresa Maria Frota. Metodologias qualitativas na sociologia. 2. ed. Petrópolis: Vozes, 1990.

KENSKI, V. M. Educação e Tecnologias: o novo ritmo da informação. 7 ed. Campinas: Papirus, 2007.

LIBREOFFICE. Draw. Disponível em: <https://pt-br.libreoffice.org/descubra/draw/> . Acesso em: 28 ago. 2021.

NASCIMENTO, João Kerginaldo Firmino do. Informática aplicada à educação. Brasília: Universidade de Brasília, 2007.

PEPPLOW, Luiz. A. Segurança do Trabalho. 21 ed. Curitiba: Base Editorial, 2010.

PONZETO, Gilberto. Mapa de riscos ambientais: aplicado à engenharia de Segurança do Trabalho - CIPA: NR-05. 3. ed. São Paulo: LTr, 2010. 
RANGEL, Mary. Métodos de ensino para a aprendizagem e a dinamização das aulas. Papirus Editora, 2005.

TAJRA, Sanmya Feitosa. Informática na Educação: Novas ferramentas pedagógicas para o professor na atualidade. 4 ed. São Paulo: ÉRICA, 2012. 